\title{
Comparing measured calcium and vitamin $D$ intakes with perceptions of intake in Canadian young adults: insights for designing osteoporosis prevention education
}

\author{
Alyson Holland* and Tina Moffat \\ Department of Anthropology, 1280 Main Street West, McMaster University, Hamilton, Ontario, Canada, L8S 4L8
}

Submitted 27 March 2016: Final revision received 6 February 2017: Accepted 8 February 2017: First published online 8 May 2017

\begin{abstract}
Objective: To identify the relationship between perceptions of Ca and vitamin D consumption and actual intakes to inform the design of osteoporosis prevention education.

Design: An FFQ was used to approximate usual monthly Ca and vitamin D intakes among a group of young Canadians. Qualitative interviews and a food card pile sort activity explored individuals' perceptions of nutrient intakes. The FFQ was used to assess nutrient adequacy for individual participants and the qualitative interviews and pile sort were analysed using thematic content analysis.

Setting: Hamilton, Canada.

Subjects: Sixty participants aged 17-30 years, representing varying levels of educational attainment.

Results: Seventy-eight per cent of young adults who consumed inadequate vitamin D perceived their intake as adequate, compared with $57 \%$ for Ca. Thematic analysis revealed three major themes that contributed to young adults' understandings of intake: belief their diet was correct, absence of symptoms and confusion over nutrient sources.

Conclusions: The majority of participants perceived themselves as consuming adequate amounts of $\mathrm{Ca}$ and vitamin $\mathrm{D}$, when they were actually consuming inadequate amounts according to FFQ findings. These perceptions were related to low engagement in prevention activities. Prevention education must motivate young adults to question the adequacy of their micronutrient intakes and design tailored programmes that are geared to a young adult audience.
\end{abstract}

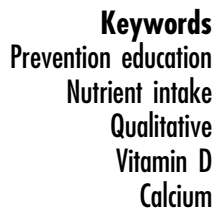

Osteoporosis is one of the most common metabolic diseases, affecting 90 million people worldwide and 2 million in Canada alone ${ }^{(1)}$. The current economic cost of osteoporosis is $\$$ CAN $2 \cdot 3$ billion in Canada ${ }^{(1,2)}, € 37$ billion $^{(3)}$ in Europe and \$US 22 billion in the USA ${ }^{(4)}$, figures that are expected to increase steadily with an ageing population that is living longer. The difficulty of arresting bone loss and building bone mass has led to a focus on osteoporosis prevention, rather than treatment ${ }^{(1,5)}$. Prevention includes pharmacological- and education-based components designed to avoid the onset of clinical symptoms of osteoporosis. Physical activity, smoking, consumption of alcohol and diet represent the modifiable components of prevention education; while all are important, the focus here is on nutrition, since $\mathrm{Ca}$ and vitamin $\mathrm{D}$ are nutrients essential for maintaining bone $\mathrm{e}^{(5-8)}$. Nutrition education is important because the end goal is to modify food consumption behaviours to increase intakes of $\mathrm{Ca}$ and vitamin $\mathrm{D}^{(9)}$. Prevention education is aimed primarily at older adults in an attempt to attenuate loss, meaning that other age groups, such as young adults (broadly defined as those aged 17-30 years), are under-represented in the osteoporosis literature ${ }^{(9)}$. However, peak bone mass is achieved in the late teens to early twenties ${ }^{(10)}$, so young adults represent an important group in the study of osteoporosis prevention because they are currently building bone and developing long-term food habits, so their food consumption behaviours have the potential to influence their long-term bone health ${ }^{(11-13)}$.

Previous research concerning osteoporosis and nutrition has focused on assessing intakes of $\mathrm{Ca}$ and vitamin $\mathrm{D}$ or intakes in relation to disease knowledge and health behaviours $^{(9,13-16)}$. Intake data allow the prevalence of nutrient inadequacy to be calculated for a specific group or population, which helps to identify where intervention is needed to increase adequacy. Young adult Estimated Average Requirements (EAR) have been established for both Ca $(800 \mathrm{mg} / \mathrm{d})$ and vitamin $\mathrm{D}(10 \mu \mathrm{g} / \mathrm{d}(400 \mathrm{IU} / \mathrm{d}))$ to maintain bone density for prevention of osteoporosis ${ }^{(17)}$. 
Ca consumption of Canadian young adults was reported as $867 \mathrm{mg} / \mathrm{d}$ for females and $1107 \mathrm{mg} / \mathrm{d}$ for males, both of which are above the $\mathrm{EAR}^{(18)}$. Canadian data on vitamin D intake, as measured from diet, indicated that young adult females consumed $3.4 \mu \mathrm{g} / \mathrm{d}(136 \mathrm{IU} / \mathrm{d})$ and males consumed $5 \cdot 4 \mu \mathrm{g} / \mathrm{d}(216 \mathrm{IU} / \mathrm{d})$, both of which fall below the $\mathrm{EAR}^{(19)}$.

Tailored prevention education is needed for young adults, as their priorities and perceptions of their own risk for developing osteoporosis differ significantly from those of older age groups ${ }^{(13,20,21)}$. Risk is an important framework for understanding engagement in prevention activities, as it is determinations about individual risk of osteoporosis that guide decisions to engage in prevention. The concept of risk narratives is used here to provide a framework for exploring how beliefs about nutrient adequacy can relate to actual nutrient intake ${ }^{(22)}$. Risk narratives are explanatory models, unique to each individual, that are constructed using the knowledge, experiences and beliefs about risk and health that an individual is exposed to throughout his/her life ${ }^{(23)}$. Young adults' attitudes and beliefs about nutrition and osteoporosis can influence their perceptions of $\mathrm{Ca}$ and vitamin $\mathrm{D}$ requirements and their own intakes, which in turn can influence the effort placed on changing their eating patterns ${ }^{(14)}$.

Individual perceptions of disease and risk play an important role in perceptions of the risk of nutrient inadequacy and the subsequent interest in prevention education. The purpose of the present study was to compare perceptions of intake with usual measured intakes of $\mathrm{Ca}$ and vitamin $\mathrm{D}$ in order to investigate young adults' awareness of their individual nutrient intakes. A risk narratives framework is used here to identify new directions for prevention education that can be tailored to young adults' understandings of their own nutrition and consumption to create more effective prevention education.

\section{Methods}

\section{Study setting and sample}

A mixed-methods approach was used to compare actual intakes with perceived intakes of $\mathrm{Ca}$ and vitamin $\mathrm{D}$ in a sample of young adults. Sample size was driven by the qualitative methods, as these were the most time-intensive for the researcher and participant, and relied on the principle of saturation $^{(24)}$. Continual transcription allowed for monitoring of themes and when theme saturation was achieved (no new themes emerging), recruitment was arrested. Participant interviews were conducted between October 2013 and April 2014 by a trained researcher. All participants completed a sociodemographic questionnaire that collected data on education, socio-economic status, age and gender. The sample consisted of sixty multi-ethnic participants, consisting of thirty men and thirty women, who were living in Hamilton, Ontario, Canada. Participants were asked to self-identify their ethnocultural affiliation, which created a large range of responses that could not be appropriately broken down into set categories. All participants were between the ages of 17 and 30 years, following a broadly inclusive definition of young adults that includes both students and young professionals ${ }^{(25,26)}$. The majority of participants fell into the 19-24 years old range, due to the high number of university and college students surveyed. The large proportion of students in the sample is consistent with the enrolment rates for post-secondary education in Ontario, where $88 \%$ of all young adults attend some level of post-secondary education $^{(27)}$. Participants were recruited from McMaster University (4-year degree programme), Mohawk College (2-year degree programme), post-secondary graduates who were no longer attending any educational institution, and individuals who did not attend any post-secondary education. Recruitment was accomplished using posters placed around the campuses and in the Hamilton community, as well as through the use of a social media page (Facebook) designed for the current project.

Ethics clearance was received from the McMaster University and Mohawk College research ethics boards and written consent was obtained from all participants before data collection began. In order to be included in the study, participants were required to be within the age range of 17-30 years, living or studying in Hamilton and capable of providing consent. No participants who volunteered for the study were later excluded and none chose to withdraw. All participants were provided with a grocery store gift certificate for participation. After the data were collected participants were provided with information on osteoporosis and any concerns and questions regarding osteoporosis were addressed. After participation, participants were also provided with their own $\mathrm{Ca}$ and vitamin $\mathrm{D}$ intake values.

\section{Vitamin $D$ and calcium intakes: data collection and analysis}

Nutrient intake data were collected using an FFQ that was designed to estimate usual intakes of Ca and vitamin D over the previous month from dietary and supplement sources. Supplement sources were included only for those participants who could recall the exact amount or detailed information on the brand and who indicated they consumed the supplement at least once weekly. This FFQ has been previously validated in Canadian young adults ${ }^{(28)}$. The participants were asked about thirty-seven food items with nine options for consumption frequency related to serving $\operatorname{size}^{(28)}$. Intakes were measured using a nutrient calculator based on the Canada Nutrient File provided by Dr Susan Whiting at the University of Saskatchewan.

Nutrient adequacy is the set amount of a nutrient required by an individual or population. In North America, the Institute of Medicine has established Dietary Reference Intakes for specific nutrients using the RDA (an estimate of the amount of a nutrient required for $95 \%$ of the 
population) and EAR (a more conservative measurement that estimates the amount of a nutrient required for $50 \%$ of the population) ${ }^{(17)}$. The Institute of Medicine established these Dietary Reference Intakes on the evidence for bone health outcomes associated with intakes of $\mathrm{Ca}$ and vitamin $\mathrm{D}^{(17)}$. Intakes (the reported or measured amount of a nutrient consumed) that fall below these RDA are considered inadequate. Nutrient intake adequacy for individuals was assessed using the equation to assess individual intake provided by the Institute of Medicine ${ }^{(29)}$, which utilizes the EAR for $\mathrm{Ca}$ and vitamin $\mathrm{D}$ in combination with known day-to-day variation. A modified assessment of intake for individuals was conducted for vitamin $\mathrm{D}$, as the estimate for day-to-day intake for individuals was not provided by the Institute of Medicine.

Differences between males and females for both $\mathrm{Ca}$ and vitamin $\mathrm{D}$ were compared using a Mann-Whitney $U$ test because the data were not normally distributed (as assessed using the Shapiro-Wilk test for normality). A $P$ value of less than 0.05 was considered statistically significant. Due to the small sample size it was not possible to assess differences related to sociodemographic variables such as age. The FFQ and sociodemographic questionnaire were completed before the pile sort and interview in order to avoid biasing the FFQ. Both surveys were self-administered, but a trained researcher was present to explain the surveys, answer any questions and check that all sections were filled out. The same trained researcher was responsible for all data collection, transcription and analysis.

\section{Qualitative beliefs about nutrient adequacy and risk narratives: data collection and analysis}

Qualitative data on beliefs about adequacy were explored using a pile sort activity followed by individual semistructured interviews. The purpose of the pile sort activity was to investigate perceptions of the $\mathrm{Ca}$ and vitamin $\mathrm{D}$ contents of foods. A series of twenty-eight cards with images and labels of foods that contained varying amounts of $\mathrm{Ca}$ and vitamin $\mathrm{D}$ were provided to participants (see online supplementary material, Supplemental Fig. 1). Participants were asked to first sort foods into groups containing $\mathrm{Ca}$ and then re-sort them into groups containing vitamin D. After this activity, they were asked to explain their choices. The pile sort activity was adapted from other studies that used pile sorts for food-related questions ${ }^{(30-32)}$. The goal of the pile sort in the present study was to use images of foods to stimulate conversation about the characteristics of $\mathrm{Ca}$ - and vitamin D-containing foods, not to specifically evaluate knowledge.

Interviews lasted 60-90 $\mathrm{min}$ and included questions about daily dietary practices, defining nutrition and health, beliefs about Ca and vitamin D intakes, dietary and nondietary sources of $\mathrm{Ca}$ and vitamin $\mathrm{D}$, and $\mathrm{Ca}$ and vitamin $\mathrm{D}$ knowledge. The interviews included specific questions such as 'Do you feel you are at risk for osteoporosis?', and broader questions related to bone heath such as 'How often do you think about your bones?' and 'What can you tell me about osteoporosis?'

All interviews and pile sorts were transcribed and analysed by a trained researcher following the process for qualitative content analysis outlined by Bernard ${ }^{(24)}$. This method involves using a small number of broad $a$ priori codes guided by the research question and related to risk narratives. These codes provided a framework for the initial coding process that allowed for risk-related themes to be separated from the larger transcripts. A second round of coding involved a more grounded theory approach, as codes were generated from a close reading of the transcripts. All codes were then organized using NVivo 10 qualitative data analysis software in order to create hierarchies, merge duplicates and examine relationships between themes. The final themes were identified through this process and reflect the collapsing of multiple codes into a larger overarching category representing viewpoints held by multiple participants. The pile sorts were combined with the interviews in each transcript and analysed as part of the thematic analysis.

\section{Results}

\section{Empirical measures of calcium and vitamin $D$ intakes}

The sociodemographic distribution of the sample can be seen in Table 1. While both males and females had mean Ca intakes that were above the EAR (Table 2), this was due to five individuals who had exceptionally high intakes (>1500 mg/d for females and > $2000 \mathrm{mg} / \mathrm{d}$ for males). When these outliers were removed, the mean Ca intake for females was 716 (sD 343) mg/d and for males was 787 (sD 470) mg/d, both of which fall below the EAR. The mean vitamin D intake for males was slightly below the EAR and the mean intake for females was above the EAR; however, these values were influenced by a few extremely high values $(>25 \mu \mathrm{g} / \mathrm{d}(>1000 \mathrm{IU} / \mathrm{d}))$ due to supplementation and a

Table 1 Demographic characteristics of the sample of Canadian young adults aged 17-30 years ( $N$ 60), October 2013-April 2014

\begin{tabular}{lrl}
\hline Sociodemographic variable & $n$ & $\%$ \\
\hline Age (years) & & \\
$17-19$ & 15 & $25 \cdot 0$ \\
$20-22$ & 17 & $28 \cdot 3$ \\
$23-25$ & 12 & $20 \cdot 0$ \\
$26-28$ & 10 & $16 \cdot 6$ \\
$29-30$ & 6 & $10 \cdot 0$ \\
Gender & 30 & $50 \cdot 0$ \\
Male & 30 & $50 \cdot 0$ \\
Female & & \\
Education & 6 & $10 \cdot 0$ \\
No post-secondary & 20 & $33 \cdot 3$ \\
College student & 20 & $33 \cdot 3$ \\
University student & 14 & $23 \cdot 3$ \\
Post-secondary graduate & & \\
\hline
\end{tabular}


Table 2 Daily intakes (mean, standard deviation and range) of calcium and vitamin D, overall ( $N 60)$ and by gender (males, $n 30$; females, $n$ 30), in the sample of Canadian young adults aged 17-30 years, October 2013-April 2014

\begin{tabular}{|c|c|c|c|c|c|c|c|c|c|}
\hline & \multicolumn{3}{|c|}{ Ca intake $(\mathrm{mg} / \mathrm{d})$} & \multicolumn{3}{|c|}{ Vitamin D intake $(\mu \mathrm{g} / \mathrm{d})$} & \multicolumn{3}{|c|}{ Vitamin D intake (IU/d) } \\
\hline & Mean & SD & Range & Mean & SD & Range & Mean & SD & Range \\
\hline Male & 1005 & 714 & $507-2532$ & $9 \cdot 60$ & $8 \cdot 15$ & $1 \cdot 62-21 \cdot 30$ & 384 & 326 & 65-852 \\
\hline Female & 841 & 445 & $177-1975$ & $10 \cdot 65$ & 9.00 & $1 \cdot 35-28 \cdot 85$ & 426 & 360 & $54-115$ \\
\hline Total & 923 & 595 & $177-2532$ & $10 \cdot 13$ & 8.53 & $1 \cdot 35-28 \cdot 85$ & 405 & 341 & $54-115$ \\
\hline$P$ value ${ }^{*}$ & \multicolumn{3}{|c|}{$U=410, P=0.71$} & \multicolumn{3}{|c|}{$U=409, P=0.69$} & \multicolumn{3}{|c|}{$U=409, P=0.69$} \\
\hline
\end{tabular}

*Significance of the difference between males and females was assessed using a Mann-Whitney $U$ test (significance set at $P=0.05)$.

number of very low values $(<5 \mu \mathrm{g} / \mathrm{d}(<200 \mathrm{IU} / \mathrm{d})$; Table 2$)$. Overall, very few individuals had vitamin $D$ values that met the EAR without supplementation ( $n$ 3). Ca and vitamin D supplement data were included in the mean intake of Ca (six participants) and vitamin D (seven participants) where it was provided. All Ca supplement users and six of the seven vitamin D supplement users received their supplements as part of a multivitamin. One participant specifically consumed a vitamin D supplement.

Assessment of nutrient adequacy indicated that $55 \%$ of participants were found to have inadequate intakes of $\mathrm{Ca}$ and $61 \%$ were found to have inadequate intakes of vitamin D, when compared with the EAR for the age of the individual (Fig. 1). As seen in Fig. 1, when perceptions of intake adequacy were compared with these results, 57\% (nineteen out of thirty-three) of the individuals who fell below the EAR for $\mathrm{Ca}$ intake believed that their intake was adequate. There was no statistical difference between males and females in terms of perceptions of $\mathrm{Ca}$ consumption ( $U=410, P=0.71$ ). For vitamin D intake, $78 \%$ (twenty-nine out of thirty-seven) of the individuals whose consumption fell below the EAR believed their intake to be adequate (Fig. 1). Again there was no statistical difference between males and females in their perceptions of their vitamin D intake ( $U=409, P=0.69)$.

\section{Qualitative risk narrative findings}

Thematic analysis of the qualitative interview and pile sort data resulted in the identification of three major nutrition discourses that participants expressed to explain their belief in the adequacy of their diets. Participants indicated that they relied on their perceptions of their diet as healthy, the perceived absence of any nutrition-related illnesses and the belief that $\mathrm{Ca}$ and vitamin D were present in many of the foods they ate to support their conviction that their intakes of $\mathrm{Ca}$ and vitamin $\mathrm{D}$ were adequate.

\section{The correct diet}

Participants consistently expressed the idea that they knew their $\mathrm{Ca}$ and vitamin $\mathrm{D}$ intakes were adequate because of the types of food they consumed:

'[I get enough] because it's in everything I eat. It's in the cheese that I have on everything. It's in milk that
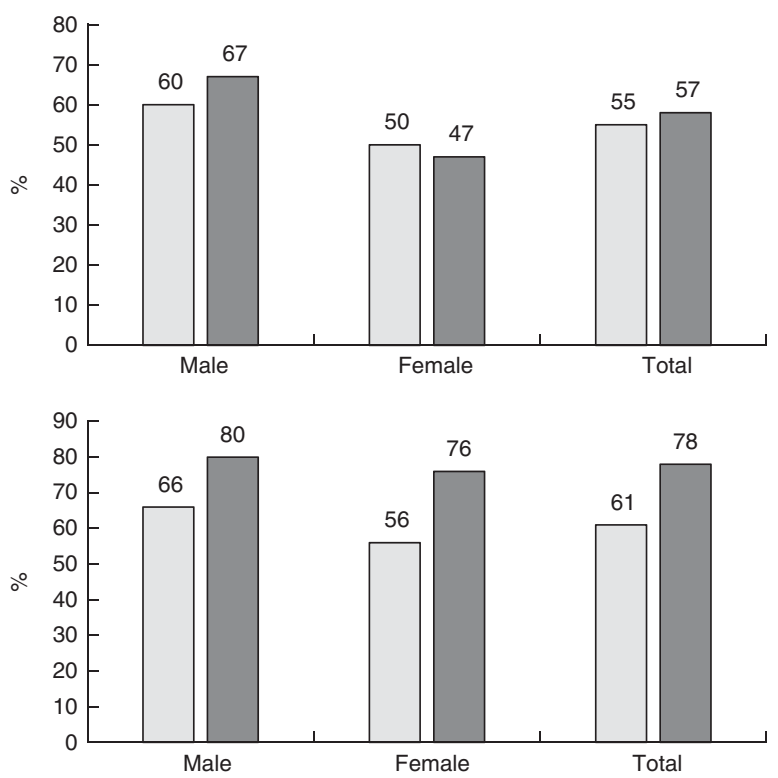

Fig. 1 Percentage of individuals deemed to have inadequate intakes ( $\square$ ) of calcium (a) and vitamin $D$ (b) according to the Estimated Average Requirement and percentage of those deemed to have inadequate intakes who perceived themselves as having adequate intakes ( $\square$ ) of calcium (a) and vitamin D (b) in the sample of Canadian young adults aged 17-30 years, October 2013-April 2014

I drink straight. It's in vegetables when I eat them.' (Male, 29 years, graduated, P\#50).

Specifically, they referred to eating the correct foods, which were foods that were viewed as good, healthy and nutrientrich. Healthy eating was understood as consuming many fruits or vegetables, while restricting 'bad' foods or nutrients:

'If I'm making a meal for dinner time [I'm] consciously ensuring that there are vegetables, that there's not too much fat.' (Male, 25 years, graduated, P\#86)

The focus on specific foods as being healthy led participants to view typical healthy foods as being rich in all the nutrients they needed. As a result, vegetables and fruits were referenced as a source of all nutrients:

'Yup. I think [I get enough]. Because I eat my greens and I eat my veggies and I get enough sun.' (Male, 26 years, college, $\mathrm{P} \# 49$ ) 
While the need to consume good foods was discussed by most participants, many tied their perceptions of adequacy directly to their consumption of dairy, or more specifically milk:

'I guess maybe I'm biased. I feel like there is a pervasive, which I'm kind of susceptible to, a pervasive feeling that if you drink milk you have healthy bones and that's like the end of the story.' (Female, 30 years, university, P\#3)

As illustrated by this participant, daily consumption of milk was enough to satisfy nutrient requirements for bone health. Similar sentiments were expressed by other participants:

'I know that I get more than enough calcium because I have a lot of dairy in my everyday meals.'

(Female, 18 years, university, $\mathrm{P \# 2}$ )

Young adults' perceptions of the adequacy of their intakes were tied to their beliefs about the required amounts of $\mathrm{Ca}$ and vitamin D. Eating enough of the correct foods (e.g. vegetables, dairy, milk) was all they needed to do and their determination of enough ranged from their 'feeling' that the amount they consumed was satisfactory to a reliance on practiced behaviours:

'Because that's exactly what I've been having all my life. Two glasses of milk every day. I have a glass of milk in the morning and I have a big glass of coffee with milk of course and just instant coffee just before I go to sleep, like just enough time before I go to sleep, like half an hour. And I haven't really had any problems with my bones, so I think it is good enough.' (Male, 28 years, college, P\#73)

This participant's assessment of his diet echoes what many expressed, that they continued to replicate the intake that was set for them as children and the lack of negative physical effects reinforced that their consumption was adequate. This quote also introduces a second theme that appeared in many of the explanations provided by the participants, the lack of noticeable symptoms of deficiency.

\section{Absence of illness \\ Participants relied on their perceived lack of illness to rationalize their belief in their Ca and vitamin D adequacy. There was an underlying conviction that nutrient inade- quacy would have obvious physical symptoms. The nature of these symptoms was defined individually by each participant, depending on how they felt Ca and vitamin D could affect the body. Commonly cited was an absence of bone pain or fracture:}

'If something were to happen to me. Maybe, like if I were to break a bone or get some kind of infection.' (Male, 22 years, non-student, P\#81)
To these participants, the absence of fractures or bone diseases indicated that their intake was adequate and that obvious physical problems would arise if they were under-consuming.

The body was viewed as the best indicator of nutrient inadequacy and paying attention to the body, and the signs it provides, was repeatedly mentioned as an important way of ensuring $\mathrm{Ca}$ and vitamin $\mathrm{D}$ adequacy. One participant expressed the need to pay attention to overall health:

'I have energy to do things, like I'm not tired. I'm not like out of shape even though I am, I'm not like excessively out of shape. Mostly like I know that I'm like a decently healthy person, not like the most healthy person. I'm not like that two percent body fat type person. But like decently healthy.' (Male, 21 years, college, P\#57)

To this individual having energy and not being tired reinforced his belief that he was healthy and taking in adequate nutrients. Another participant identified a more visceral reaction to nutrient inadequacy:

'If I don't feel good or I feel dizzy or something. I know sometimes when I don't feel good I'll be like, "Oh mom, I don't feel good. I just ate, but I feel dizzy, I don't feel like myself." She'll be like, "Oh, have a banana or oh, have some almonds." Or just have whatever it is that she tells me to have, and then I'll eat it and then like 10 minutes later I'm like, "Oh I feel so much better now." So I think your own body tells you that you're lacking something.' (Female, 20 years, college, P\#63)

For her, there was a clear and immediate connection between physical symptoms of illness and inadequacy. As long as she felt fine, she assumed she was consuming adequate amounts of nutrients.

\section{Confusion over sources}

Perceptions of adequacy were affected by young adults' beliefs about sources of $\mathrm{Ca}$ and vitamin $\mathrm{D}$, which were related to ideas about consuming the correct diet. The sources of Ca and vitamin D that participants discussed were varied and were based on a myriad of criteria that included the colour, texture, origin, value and composition of food. One participant focused extensively on the colour/texture of food to identify $\mathrm{Ca}$ :

'Tofu it's got to be [high in calcium] because it was white, so just by association. I guess avocado and hummus are similar. I guess it's just the creaminess. Like chickpeas and avocado are creamy and I associate that with calcium.' (Male, 29 years, graduated, P\#50)

Using these characteristics led him to identify $\mathrm{Ca}$ in more foods than actually contain the nutrient. Ca-containing foods were identified as: healthy foods, dairy foods or dairy 
alternatives, milk, white or creamy foods, good foods rather than junk foods, and foods that are high in other vitamins. One participant stated:

'Bananas, I know bananas have potassium in them. I don't know of anything else, but I figured because maybe it has one thing, it has another.' (Male, 19 years, college, $\mathrm{P \# 47)}$

Milk was most commonly associated with $\mathrm{Ca}$; often it was the only food that participants felt they were sure contained $\mathrm{Ca}$ :

'My only familiarity with calcium is that it's contained in milk. And I know, and so by association any type of dairy products.' (Male, 28 years, university, $\mathrm{P \# 30)}$

Alternatives to dairy (soya, coconut, almond and rice milk) were also viewed as high in $\mathrm{Ca}$, although the reasons for this varied; some participants felt that dairy alternatives would be naturally high because they could be used in place of milk:

'Soy, I just kind of figured it's the alternative to milk so I just figured most of the products would be a similar replacement for dietary needs.' (Male, 21 years, university, $\mathrm{P \# 6)}$

While participants expressed confidence in their assessment of Ca-containing foods, identifying vitamin D sources produced confusion. Although participants correctly identified the sun as a source, understanding how vitamin D was obtained was more difficult:

'To be honest vitamin $\mathrm{D}$ is the one thing that has confused me so much. Because I hear it comes from the sun and I don't understand how that happens. I don't understand, because I see vitamins as more of a physical substance.' (Male, 20 years, college, $\mathrm{P \# 69)}$

While Ca was understood as a physical substance that existed as a component of food, vitamin D was less tangible and so more difficult to locate in specific foods. Participants drew associations between vitamin D and foods they perceived as natural or those that grew in the sun:

'Oranges, obviously. That's what they're really known for, their vitamin D.' (Male, 19 years, college, P\#45)

This led to the misidentification of specific foods as containing vitamin $\mathrm{D}$, like oranges, even when they do not.

\section{Discussion}

Overall participants in the present study perceived themselves as consuming adequate amounts of $\mathrm{Ca}$ and vitamin $\mathrm{D}$, although they did not define the concept of adequate amounts. In contrast, the majority of participants, as measured by the FFQ, were deemed to be consuming inadequate amounts of both nutrients.
The three nutrition discourses raised by the interviews and pile sort serve to aid in explaining and contextualizing the results from the FFQ. Young adults developed risk narratives to address their own potential for nutrient inadequacy. The justifications they presented to explain their own adequacy, as reflected in the nutrition discourses identified here, are a product of the influence of cultural, educational and governmental spheres, as well as family and peer groups. Their perceptions of $\mathrm{Ca}$ and vitamin $\mathrm{D}$ adequacy reflected a combination of their own experience as food consumers throughout their lives, their general knowledge of health and healthy eating, their specific experiences with $\mathrm{Ca}$ and vitamin $\mathrm{D}$, and the larger cultural nutrition narratives they are taught. Each theme contributed to their overall understanding of their perceived risk and relied on specific narratives they had constructed. The concept of healthy eating was viewed as a binary: either they 'ate healthy' or they 'ate unhealthy'. This binary view reflects how mainstream discussions of consumption are structured into the healthy/unhealthy dichotomy ${ }^{(33-35)}$. The dominant food discourse that is entrenched in food guides and expressed through nutrition education produces a nutrition narrative that focuses on the attainment of a prescriptive healthy diet ${ }^{(36)}$. 'Eating healthy' comes to mean an individual is providing the body with all the nutrients that it needs, in the correct amounts, which means consuming adequate nutrients. As a result, the narrative of nutrient adequacy woven by participants comes to reflect the viewpoint that consumption of $\mathrm{Ca}$ and vitamin $\mathrm{D}$ does not necessarily require intentional choices related to those nutrients, but only mindful eating of generally healthy foods. This view is reflected in the low use of supplements (only seven participants out of sixty) in this population. Separate Ca and vitamin D supplements were not viewed as necessary, as all but one participant received their supplements as part of a multivitamin. Only one participant intentionally consumed vitamin $\mathrm{D}$ and that was through direction from a parent, not a personal concern about intake.

The existence of the healthy body presupposes the correct consumption of nutrients. The conviction that nutrient deficiency would produce illness served as a way of rationalizing this belief in the healthy diet as protective. Participants drew on their knowledge that some nutrients (such as $\mathrm{Fe}$ ) produce specific negative health effects when an individual is deficient and applied it widely to all nutrients. The knowledge participants had gained about healthy eating through their own experiences as consumers, along with the absence of illness, allowed them to construct a risk narrative that placed them at low risk of nutrient inadequacy. While a broad age range was surveyed, it is worth noting that the same nutrition discourses were found at both ends of the age range. While motivations towards consumption were different for 30-year-olds than for 17-year-olds, the rationalizations behind perceptions of adequacy were not substantially different. 
The problem for designing prevention that arises from this situation is that most existing prevention education programmes on bone health, such as through Osteoporosis Canada and the Dairy Farmers of Canada's 'get enough' campaign, focus on educating those who perceive themselves at risk. People who believe their own intake to be adequate do not consider themselves at risk and consequently will not actively engage with prevention education. The individuals who would benefit from prevention education are likely not receiving it as their explanatory models and individual risk narratives minimize the importance of nutrition while assuming adequate intakes of $\mathrm{Ca}$ and vitamin $\mathrm{D}$. Cultivating young adults' interest in information on $\mathrm{Ca}$ and vitamin $D$ inadequacy first requires individuals to recognize their own need to increase these micronutrients.

Increasing decision making related to $\mathrm{Ca}$ and vitamin $\mathrm{D}$ therefore requires making these micronutrients larger players in the national nutritionscape. The minimization of bone health and its relegation to the domain of older adults and growing children leave a gap for young adults that is filled with concern over 'bad' nutrients (fats, carbohydrates, sugars and salts) and inadequately defined notions of nutritional health. Nutrition education needs to direct young adults in consciously considering their own intakes of nutrients, beyond the 'bad four'. Engaging young adults with osteoporosis prevention information is a more complex process than simply presenting information. It requires consideration of the social and cultural environment in which young adults come to think about their own nutritional health to create interventions that counteract the justifications they use for rationalizing beliefs about their own nutrient adequacy. Nutrition decisions represent an important aspect of osteoporosis prevention education and do not exist in a vacuum. Developing approaches that target young adults' nutrition is needed in concert with initiatives that focus on other prevention activities such as physical activity in order to develop and maintain healthy bones.

\section{Limitations}

Due to the inclusion of qualitative results along with the consumption data, the sample size ( $n$ 60) was smaller than in other nutrition studies, which limits the generalizability of the results to the larger Canadian population. There are problems inherent in the use of FFQ, most notably that usual intake is difficult to capture and relies on self-reported data. While the FFQ was designed to account for intake over a month in order to more closely estimate usual intakes, all intake data were self-reported and subject to intentional and unintentional misreporting. Since the FFQ was administered only once, it was not possible to account for variation over time, although validation of the FFQ by Wu et $a l^{(28)}$ showed good agreement with previous administrations. The Dietary Reference Intakes for $\mathrm{Ca}$ and vitamin $\mathrm{D}$ are based on a small number of studies, so thresholds for adequacy must be interpreted cautiously. Additionally, assessing adequacy of vitamin D from diet is problematic, since vitamin $\mathrm{D}$ is also synthesized from exposure to UV radiation, meaning that dietary estimates might underestimate intake.

\section{Conclusion}

The results of the present study reveal a disconnect between $\mathrm{Ca}$ and vitamin $\mathrm{D}$ intakes and individual perceptions of these intakes. Young adults are under-consuming Ca and vitamin D and therefore increasing their potential future risk for osteoporosis. In order to rectify this problem, the delivery of prevention information needs to be adapted to young adults who are not engaged with nutrition self-care. Depictions of osteoporosis prevention with respect to $\mathrm{Ca}$ and vitamin D inadequacy should be distanced from a focus on the elderly and address the prevalence of inadequacy in younger life stages as well as the consequences of inadequacy. Before young adults can be engaged in a discussion about inadequacy, they must first be made aware of the need for Ca and vitamin D. Linking vitamin D to bone health in the minds of consumers and promoting awareness of $\mathrm{Ca}$ mean encouraging young adults to question their own intakes rather than simply providing ways of attaining these nutrients. By reframing messages to deliver $\mathrm{Ca}$ and vitamin $\mathrm{D}$ information that is tailored to young adults, there is a greater potential for developing risk narratives to more accurately reflect the importance of nutrition and a focus on inadequacy, as it pertains to bone health. Additionally, further research is needed to explore perceptions of the role of these nutrients in young adults' diets to confirm the generalizability of these results in the greater Canadian population and other populations worldwide to inform osteoporosis prevention and education programmes.

\section{Acknowledgements}

Acknowledgements: The authors would like to extend thanks to the study participants and to Dr Stephanie Atkinson and Dr Megan Brickley for their insight and contributions to the manuscript. Financial support: This research was partially funded by the Ontario Graduate Scholarship. The Ontario Graduate Scholarship had no role in the design, analysis or writing of this article. Conflict of interest: Neither author has any conflict of interest. Authorship: Both authors were involved in the design and analysis of this study and in the creation of the manuscript. Ethics of human subject participation: This study was conducted according to the guidelines laid down in the Declaration of Helsinki and all procedures involving human subjects/patients were approved by the McMaster University and Mohawk College institutional review boards. Written informed consent was obtained from all participants. 


\section{Supplementary material}

To view supplementary material for this article, please visit https://doi.org/10.1017/S1368980017000386

\section{References}

1. Tarride JE, Hopkins RB, Leslie WD et al. (2012) The burden of illness of osteoporosis in Canada. Osteoporos Int $\mathbf{2 3}$, 2591-2600.

2. Public Health Agency of Canada (2010) What is the Impact of Osteoporosis in Canada and What are Canadians Doing to Maintain Healthy Bones? Ottawa: PHAC.

3. Hernlund E, Svedbom A, Ivergard M et al. (2013) Osteoporosis in the European Union: medical management, epidemiology, and economic burden. Arch Osteoporos 8, 136.

4. Blume SW \& Curtis JR (2011) Medical costs of osteoporosis in the elderly Medicare population. Osteoporos Int 22, 1835-1844.

5. World Health Organization (2003) Prevention and Management of Osteoporosis. Report of a WHO Scientific Group. WHO Technical Report Series no. 921. Geneva: WHO.

6. Uusi-Rasi K, Sievanen H, Pasanen M et al. (2002) Associations of calcium intake and physical activity with bone density and size in premenopausal and postmenopausal women: a peripheral quantitative computed tomography study. J Bone Miner Metab 17, 544-552.

7. Sampson W (2002) Alcohol and other factors affecting osteoporosis risk in women. Alcohol Res Health 26, 292-298.

8. Karasik D \& Ferrari SL (2008) Contribution of genderspecific genetic factors to osteoporosis risk. Ann Hum Genet 72, 696-714.

9. Tussing L \& Chapman-Novakofski K (2005) Osteoporosis prevention education: behavior theories and calcium intake. J Am Diet Assoc 105, 92-97.

10. Baxter-Jones ADG, Faulkner RA, Forwood MR et al. (2011) Bone mineral accrual from 8 to 30 years of age: an estimation of peak bone mass. J Bone Miner Res 26, 1729-1739.

11. Chan MF, Kwong WS, Zang Y et al. (2006) Evaluation of an osteoporosis prevention education programme for young adults. $J$ Adv Nurs 57, 270-285.

12. Kasper MJ, Peterson MG \& Allegrante JP (2001) The need for comprehensive educational osteoporosis prevention programs for young women: results from a second osteoporosis prevention survey. Arthritis Rheum 45, 28-34.

13. Ziccardi SL, Sedlak CA \& Doheny MO (2004) Knowledge and health beliefs of osteoporosis in college nursing students. Orthop Nurs 23, 128-133.

14. Chang S-F (2006) A cross-sectional survey of calcium intake in relation to knowledge of osteoporosis and beliefs in young adult women. Int J Nurs Pract 12, 21-27.

15. Piaseu N, Schepp K \& Belza B (2002) Causal analysis of exercise and calcium intake behaviors for osteoporosis prevention among young women in Thailand. Health Care Women Int 23, 364-376.

16. Swaim RA, Barner JC \& Brown CM (2008) The relationship of calcium intake and exercise to osteoporosis health beliefs in postmenopausal women. Res Social Adm Pharm 4, 153-163.

17. Institute of Medicine (2011) Dietary Reference Intakes for Calcium and Vitamin D [AC Ross, CL Taylor, AL Yaktine et al., editors]. Washington, DC: The National Academies Press.
18. Vatanparast H, Dolega-Cieszkowski JD \& Whiting S (2009) Many adult Canadians are not meeting current calcium recommendations from food and supplement intake. Appl Physiol Nutr Metab 34, 191-196.

19. Zhou W, Langsetmo L, Berger C et al. (2013) Longitudinal changes in calcium and vitamin $\mathrm{D}$ intakes and relationship to bone mineral density in a prospective populationbased study: the Canadian Multicentre Osteoporosis Study (CaMos). J Musculoskelet Neuronal Interact 13, 470-479.

20. Backett-Milburn K, Parry O \& Mauthner N (2000) 'I'll worry about that when it comes along': osteoporosis, a meaningful issue for women at mid-life? Health Educ Res 15, 153-162.

21. Edstrom KM \& Devine CM (2001) Consistency in women's orientations to food and nutrition in midlife and older age: a 10-year qualitative follow-up. J Nutr Educ 33, 215-223.

22. Panter-Brick C \& Fuentes A (2009) Health, risk and adversity: a contextual view from anthropology. In Health, Risk, and Adversity, pp. 1-12 [C Panter-Brick and A Fuentes, editors]. New York: Berghahn Books.

23. Kleinman A (1988) The Illness Narratives: Suffering, Healing and the Human Condition. New York: Basic Books.

24. Bernard H (2011) Research Methods in Anthropology: Qualitative and Quantitative Approaches, 5th ed. Lanham, MD: AltaMira.

25. Geiger A \& Castellino SM (2011) Delineating the age ranges used to define adolescents and young adults. J Clin Oncol 29, 492-493.

26. Butow P, Palmer S, Pai A et al. (2010) Review of adherencerelated isues in adolescents and young adults with cancer. J Clin Oncol 28, 4800-4809.

27. Norrie K \& Lin S (2009) Postsecondary Education Attainment and Participation in Ontario. Toronto: Higher Education Quality Council of Ontario.

28. Wu H, Gozdzik A, Barta JL et al. (2009) The development and evaluation of a food frequency questionnaire used in assessing vitamin D intake in a sample of health young Canadian adults of diverse ancestry. Nutr Res 29, $255-261$.

29. Institute of Medicine (2000) Dietary Reference Intakes: Applications to Dietary Assessment. Washington, DC: The National Academies Press.

30. Kumanyika SK, Tell GS, Shemanski L et al. (1997) Dietary assessment using a picture-sort approach. Am J Clin Nutr 65, 4 Suppl., 1123S-1129S.

31. Yaroch AL, Resnicow K, Davis M et al. (2000) Development of a modified picture-sort food frequency questionnaire administered to low-income, overweight, African-American adolescent girls. J Am Diet Assoc 100, 1050-1056.

32. Quintiliani LM, Campbell MK, Haines PS et al. (2008) The use of the pile sort method in identifying groups of healthful lifestyle behaviours among female community college students. J Am Diet Assoc 108, 1503-1507.

33. Chapman G \& Maclean H (1993) 'Junk food' and 'healthy food': meanings of food in adolescent women's culture. J Nutr Educ 25, 108-113.

34. Ristovski-Slijepcevic S, Chapman GE \& Beagan BL (2008) Engaging with healthy eating discourse(s): ways of knowing about food and health in three ethnocultural groups in Canada. Appetite 50, 167-178.

35. Watt RG \& Sheiham A (1997) Towards an understanding of young people's conceptualisation of food and eating. Health Educ J 56, 340-349.

36. Bush MAA, Martineau C, Pronk JA et al. (2007) Eating Well with Canada's Food Guide: 'a tool for the times'. Can J Diet Pract Res 68, 92-96. 